\title{
Adaptive Vibration Condition Monitoring Techniques for Local Tooth Damage in Gearbox
}

\author{
Kobra Heidarbeigi (Corresponding author) \\ Mechanical Engineering of Agricultural Machinery Department \\ School of Agricultural Engineering and Technology, University of Tehran, Karaj, Iran \\ E-mail: kobra.heidarbeigi@gmail.com \\ Hojat Ahmadi \\ Mechanical Engineering of Agricultural Machinery Department \\ School of Agricultural Engineering and Technology, University of Tehran, Karaj, Iran \\ M.Omid \\ Mechanical Engineering of Agricultural Machinery Department \\ School of Agricultural Engineering and Technology, University of Tehran, Karaj, Iran
}

\begin{abstract}
Vibration analysis that is the main conditions monitoring techniques for machinery maintenance and fault diagnosis, in rotating parts of tractor MF-285 for optimizing them is important. Practical experience has shown that this technique in a machine condition monitoring program provides useful reliable information, bringing significant cost benefits to industry. The objective of this study is to investigate the correlation between vibration analysis and fault diagnosis tractor gearbox. This was achieved by vibration analysis and investigating different operating conditions of tractor (M-F) gearbox. This gearbox coupled to the electromotor that was initially run under normal operating conditions and its speed was at two levels, 500 and 1000 RPM respectively. Even tooth in a gearbox is alternately meshing and detaching during its operation and the loading condition of the tooth is alternately changing. Hence, the gear conditions were considered to be normal gearbox and worn and brokenteeth gears faults with the aim of fault detection and identification. Vibration data was collected from the inspected gearbox and are used for compare with vibration spectra in normal condition of healthy machine, in order to quantify the effectiveness of the Vibration condition monitoring technique. The results from this study have given more understanding on the dependent roles of vibration analysis in predicting and diagnosing machine faults.
\end{abstract}

Keywords: Vibration condition monitoring, Gearbox, Fault diagnosis

\section{Introduction}

Tractor, as the most important agricultural machinery, has main share in planting, retaining and harvesting operations and then in mechanization sector. Hence, in order to reach sustainable agricultural and to increase mechanization level quality and manufacturing technology of this agricultural machinery and also its quantity must be reached to optimum level. Above statements show the importance of condition monitoring in gearbox of tractor MF-285 for optimizing them. In this regard, vibration condition monitoring in tooth gears of this tractor was studied. For years, condition monitoring of power transmission has been deemed imperative. Thus, gearboxes, the core of power transmission, have received considerable attention in the field of condition monitoring and fault diagnosis. In particular, gear localized defects have been extensively studied, since a large percent $(60 \%)$ of gearbox damages are due to gear faults, which in turn are mostly initiated by localized defects. Vibrations externally measured on a gearbox have been used to monitor the operating condition of the gearbox and diagnose the fault, if there is any, without interfering with the normal operation. The most common method employed for examining mechanical vibration is spectral analysis. Condition monitoring and fault diagnostics is useful for ensuring the safe running of machines [Peng and Chu, 2004]. Vibrations signals are often used for fault signals diagnosis in mechanical systems since them often carry dynamic information from mechanical elements. These mechanical signals normally consist of a combination of the fundamental frequency with a narrowband frequency component and the harmonics. Most of these are related to the revolutions of the rotating system since the energy of vibration is increased when a mechanical element is damaged or worn. Some of the conventional techniques used for fault signals diagnosis include power spectra in time domain or frequency 
domain, and they can provide an effective technique for machinery diagnosis provided that there is the assumption that the signals are stationary[Peng and Chu, 2004]. By measuring and analyzing the vibration of a machine, it is possible to determine both the nature and severity of the defect, and hence predict the machine's useful life or failure point. The main advances in vibration analysis in recent years are the development in signal processing techniques, for vibration diagnostics of gearing systems [Ebersbach et al, 2006]. Early work on the formalization of vibration diagnostics using spectral analysis [Blackman et al, 1958] progressed slowly through the 1960s, mainly due to the expense of analysis equipment. The development of the Fast Fourier Transform (FFT) in 1965 [Cooley and Tukey, 1965] allowed the development of commercial real-time spectral analyzers and, as the use of these analyzers become more widespread, a number of authors describe the vibration effects of various machine faults and how these could be diagnosed using spectral analysis [White, 1972, Braun. S, 1987, Minns and, 1972, Swansson, 1980, Randall, 1987]. In the mid 1970s, Stewart [Stewart, 1977] made a significant contribution to the use of vibration analysis as a diagnostic tool for machine faults, especially for gear faults. Further work by Randall [Randall, 1982] and McFadden [McFadden, 1985] in the underlying causes of gear vibration resulted in a better understanding of the correlation between Stewart's figures of merit and mechanical condition. McFadden [McFadden, 1988] showed the importance of phase modulation in the diagnosis of cracks and outlined a signal parameter sensitive to phase modulation. In this paper, investigate the correlation between vibration analysis and gearbox (Massy Ferguson-165) fault diagnosis. This was achieved by vibration analysis of a Massy Ferguson gearbox. A series of tests were conducted under the operating hours of gearbox. Vibration data was regularly collected. Overall vibration data produced by vibration analysis was compared with previous data. Numerical data produced by vibration analysis were compared with vibration spectra in standard of healthy gearbox, in order to quantify the effectiveness of the vibration condition monitoring technique. The results from this paper have given more understanding on the dependent roles of vibration condition monitoring in predicting and diagnosing of electromotor faults.

\section{Experimental set-up}

The test rig used for the experimentation was a gearbox. The experimental setup to collect dataset consists of Massey Ferguson gearbox, an electrical motor with two independent variable speeds that drive the system (details of electromotor are given in Table 1), a triaxial accelerometer (X-Viber, VMI is manufacturer) and four shock absorbers under the base of test-bed. Test-bed was designed to install gearbox, electric motor and four shock absorbers under bases to cancel out vibrations. This gearbox coupled to the electromotor that was initially run under normal operating conditions and its speed was at two levels, 500 and 1000 RPM respectively. All vibration signals were collected from the experimental testing of gearbox using the accelerometer which was mounted on the outer surface of the bearing case of input shaft of the gearbox. For each configuration different fault conditions were tested that were worn, broken teeth of gear and one faultless condition. The signals from the accelerometer were recorded in a portable condition monitoring signal analyzer.

\subsection{Damaged Gear}

The gear set was damaged by removing a portion of a tooth from the pinion gear. This damage was achieved by filing down a section of the tooth, such that the driven gear would impact the sharpened lip of the fault at the beginning and end of the gear meshing cycle.

Gear sets generate tones known as the gear mesh frequency. The gear mesh frequency is calculated via equation 1.

$G M F=$ No.ofTeeth $\times R P M$

The corresponding spike at this frequency generally amplifies as gear damage increases [Andy et al, 2003].

\section{Results and Discussion}

The most basic form of vibration analysis is called an overall vibration measurement. This reading provides a single number that describes the total amount of vibration energy being emitted by a machine. The idea is that more vibration indicates a problem. Signal data was acquired for machine conditions, including: a normal gearbox, worn and broken-teeth gears of these machine conditions at operating speeds of 500 and $1000 \mathrm{rpm}$. Data analysis required comparing the plots obtained for each test condition to those expected for the specific machine faults simulated. Prominent frequency spikes determined from the time and frequency domain graphs were also compared to the theoretical vibration fault signatures. The gear damage tests successfully illustrated the theoretical predictions at a rotational speed of 500 and $1000 \mathrm{rpm}$. The results showed that the RMS values for healthy gearbox at $500 \mathrm{rpm}$ (1000 rpm was the same) were on acceptable status (Figure 1). The results showed that the RMS values for the worn and broken gear at $500 \mathrm{rpm}$ (at $1000 \mathrm{rpm}$ ) were on critical status (Figure 2 and 
3). Measurement values and mean of them were higher than the RMS value of gearbox in healthy condition. Figure 4 (at $500 \mathrm{rpm}$ ) and figure 5 (at $1000 \mathrm{rpm}$ ) showed the overall vibrations of worn and broken gear condition. As can be seen in figures, the prominent frequency peak occurred with high accuracy near the predicted value of gear mesh frequency, as shown in Table 2.

Vibration analysis technique has been used to assess the condition of the gearbox and diagnose any problems of that. The results from vibration analysis of our experimental research indicate our defaults those made in our gearbox. Vibration analysis of gearbox discovered the worn and broken teeth in gears. The correlation between the vibration analysis and fault diagnosis was excellent as vibration technique was able to pick up on different issues, thus presenting a broader picture of the machine condition. Vibration analysis detected a continuing gear defect along with a possibility of mechanical faults of the outer casing from assembly. Vibration analysis technique was capable in covering a wider range of machine diagnostics and faults within the gearbox.

\section{Conclusions}

The results clearly indicate a significant variation in vibration trend as a function of operating conditions. The experimental results demonstrated that the vibration monitoring rig modeled various modes of machine failure was indeed capable of both independently and simultaneously generate common machine faults. In this research we have been made an experimental test system that we were able to perform practical tests on the constructed rig to confirm the expected theoretical frequencies that we needed. This research was offered complementary strengths in root cause analysis of machine failure, and natural allies in diagnosing machine condition. It reinforces indications correlation between vibration condition monitoring and fault diagnosis for gearbox. Both amplitude of the dominating peak and its location along the frequency axis changes in various conditions of gear. The data indicate that it is not possible to conclude that the cause of real world machinery malfunction is fault gear just by looking at a single vibration spectrum at an operating condition. A careful examination is essential to differentiate fault gear from other sources of vibration. The corresponding stress will depend upon the stiffness of the machine structure. The frequencies of peak vibration amplitude, set locations and directions were inconsistent even with speed and coupling held constant. Increased speed also caused increased peak vibration with frequency shifts that did not correlate with the speed. For predictive maintenance applications where the goal is machinery health monitoring, it is sufficient to realize that the problem is complex. One can routinely trend the vibration spectra until it becomes severe. But for root cause analysis, one must exercise caution and perform a detailed analysis. Obviously, the rules provided in training courses and wall charts are doubtful at best.

\section{Acknowledgment}

Acknowledgment is made to the University of Tehran for its concentration for this research.

\section{References}

Andy C., C. Tan, L. Katie, McNickle and L. Daniel Timms. (2003). A Practical Approach to Learning Vibration Condition Monitoring, World Transactions on Engineering and Technology Education, 2 (2).

Blackman, R.B and J.W. Tukey. (1958). The Measurement of Power Spectra. Dover Publications, New York. Braun, S. (1987). Mechanical Signature Analysis, Academic Press Inc, London.

Ebersbach, S., Z. Peng, N.J. Kessissoglou. (2006). The investigation of the condition and faults of a spur gearbox using vibration and wear debris analysis techniques, Wear 260: 16-24. Available online at www.sciencedirect.com.

Cooley, J.W and J.W. Tukey. (1965). An Algorithm for the Machine Calculation of Complex Fourier Series. Mathematics of Computing, 19: 297-301.

McFadden, P.D. (1985). Analysis of the vibration of the input bevel pinion in RAN Wessex helicopter main rotor gearbox WAK143 prior to failure, Aero Propulsion Report 169, Department of Defence, Aeronautical Research Laboratory.

McFadden, P.D. (1988). Determining the Location of a Fatigue Crack in a Gear from the Phase of the Change in the Meshing Vibration, Mechanical Systems and Signal Processing, 2(4): 403-409.

Minns, H and R.M. Stewart. (1972). An Introduction to Condition Monitoring with Special Reference to Rotating Machinary. Workshop in On-Condition Maintenance, Section 8, Institude of Sound and Vibration Research, University of Southampton.

Peng, Z.K., F.L. Chu. (2004). Application of the wavelet transform in machine condition monitoring and fault diagnostics. Mechanical Systems and Signal Processing, 18: 199-221. 
Peng, Z.K., F.L. Chu. (2004). Extraction of Gearbox Fault Features from Vibration Signal Using Wavelet Transform. J. Physics: Conference Series 48: 490-494.

Randall, R.B. (1987). Frequency Analysis, Bruel and Kjaer, Copenhagen, $3^{\text {rd }}$ edition.

Randall, R.B. (1982). A New Method of Modeling Gear Faults, J. Mechanical Design, 104: 259-267.

Stewart, R.M. (1977). Some Useful Data Analysis Techniques for Gearbox Diagnostics, University of Southampton Report MHM/10/77.

Swansson, N.S. (1980). Application of Vibration Signal Analysis Techniques to Signal Monitoring. Conference on Friction and Wear in Engineering, Institution of Engineers, Australia, 262-267.

White, C.J. (1972). Detection of Gearbox Failure. Workshop in On-Condition Maintenance, Section 7, Institute of Sound and Vibration Research, University of Southampton.

Tables:

Table 1. Detail of Electromotor.

Table 2. Fundamental Gear Damage Frequency.

Table 1. Detail of Electromotor.

\begin{tabular}{cc}
\hline Electromotor & Description \\
\hline Electromotor capacity $(\mathrm{kW})$ & $1.5(2 \mathrm{HP})$ \\
Motor driving speed $(\mathrm{rpm})$ & Variable \\
Voltage & $380 \mathrm{v}$ \\
Phase & Three phase \\
Ambient air temperature $\left({ }^{\circ} \mathrm{C}\right)$ & $\approx 25$ \\
Non driven end bearing & FAG 6205 \\
Driven end bearing & FAG 6205 \\
\hline
\end{tabular}

Table 2. Fundamental Gear Damage Frequency.

\begin{tabular}{cccc}
\hline $\begin{array}{c}\text { Shaft Speed } \\
(\mathrm{rpm})\end{array}$ & $\begin{array}{c}\text { Theoretical Frequency } \\
(\mathrm{Hz})\end{array}$ & \multicolumn{3}{c}{ Experimental Central Frequency(Hz) } \\
\cline { 3 - 5 } & & Broken & Worn \\
& 366.67 & 345.5 & 400 \\
1000 & 733.33 & 701.5 & 795.5 \\
\hline
\end{tabular}


Figures:

Figure 1. Frequency spectrum of the healthy gear at A) $500 \mathrm{rpm}, \mathrm{B}) 1000 \mathrm{rpm}$.

Figure 2. Frequency spectrum of the worn gear at A) $500 \mathrm{rpm}, \mathrm{B}) 1000 \mathrm{rpm}$.

Figure 3. Frequency spectrum of the broken gear at A) 500rpm, B) 1000rpm.

Figure 4. Comparison of Overall vibrations of gear in healthy and won and broken conditions at $500 \mathrm{rpm}$. The graphs illustrate the effect of speed on the trend.

Figure 5. Comparison of Overall vibrations of gear in healthy and won and broken conditions at $1000 \mathrm{rpm}$. The graphs illustrate the effect of speed on the trend.

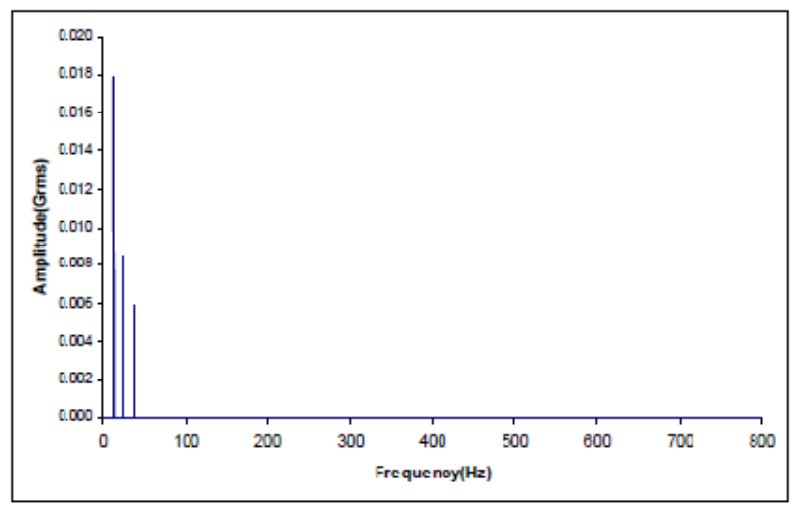

(A)

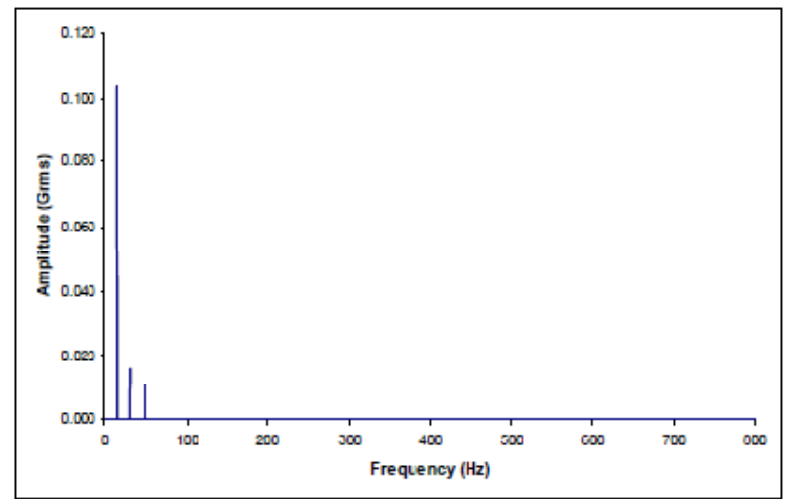

(B)

Figure 1. Frequency spectrum of the healthy gear at A) $500 \mathrm{rpm}, \mathrm{B}) 1000 \mathrm{rpm}$.

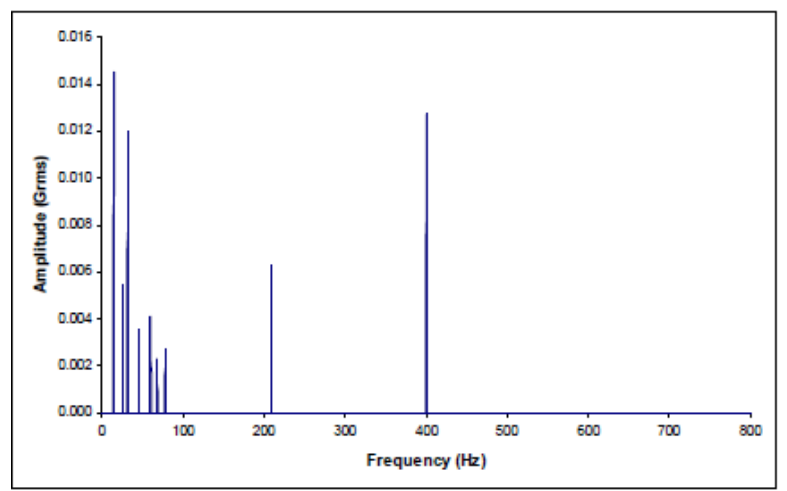

(A) 


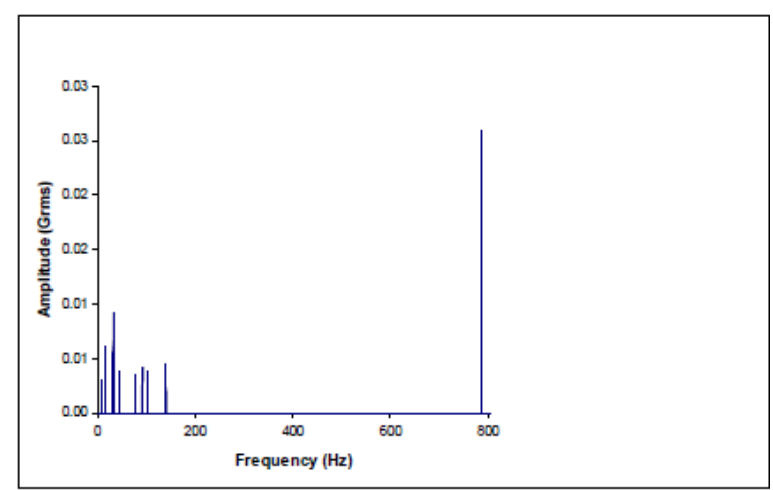

(B)

Figure 2. Frequency spectrum of the worn gear at A) $500 \mathrm{rpm}, \mathrm{B})$ 1000rpm.

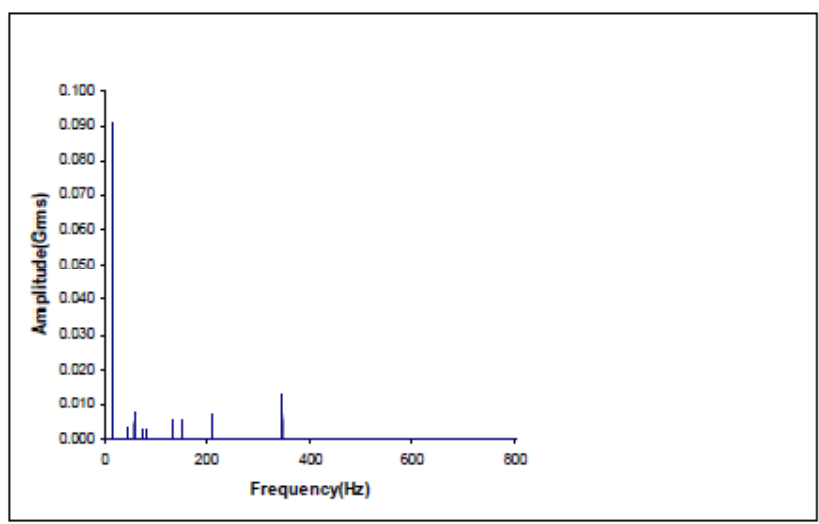

(A)

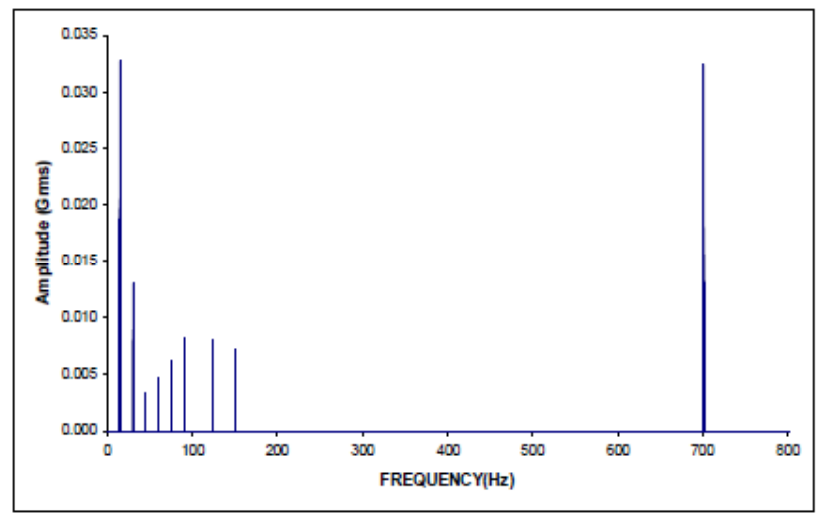

(B)

Figure 3. Frequency spectrum of the broken gear at A) 500rpm, B) 1000rpm. 


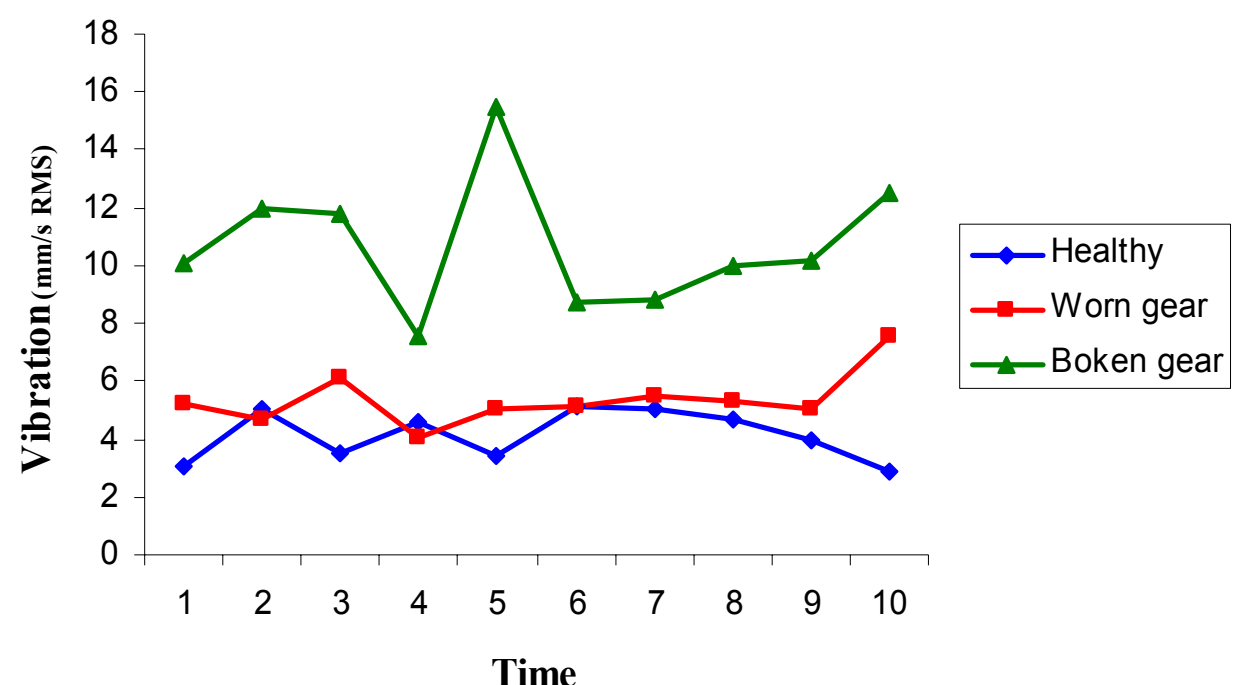

Figure 4. Comparison of Overall vibrations of gear in healthy and won and broken conditions at $500 \mathrm{rpm}$. The graphs illustrate the effect of speed on the trend.

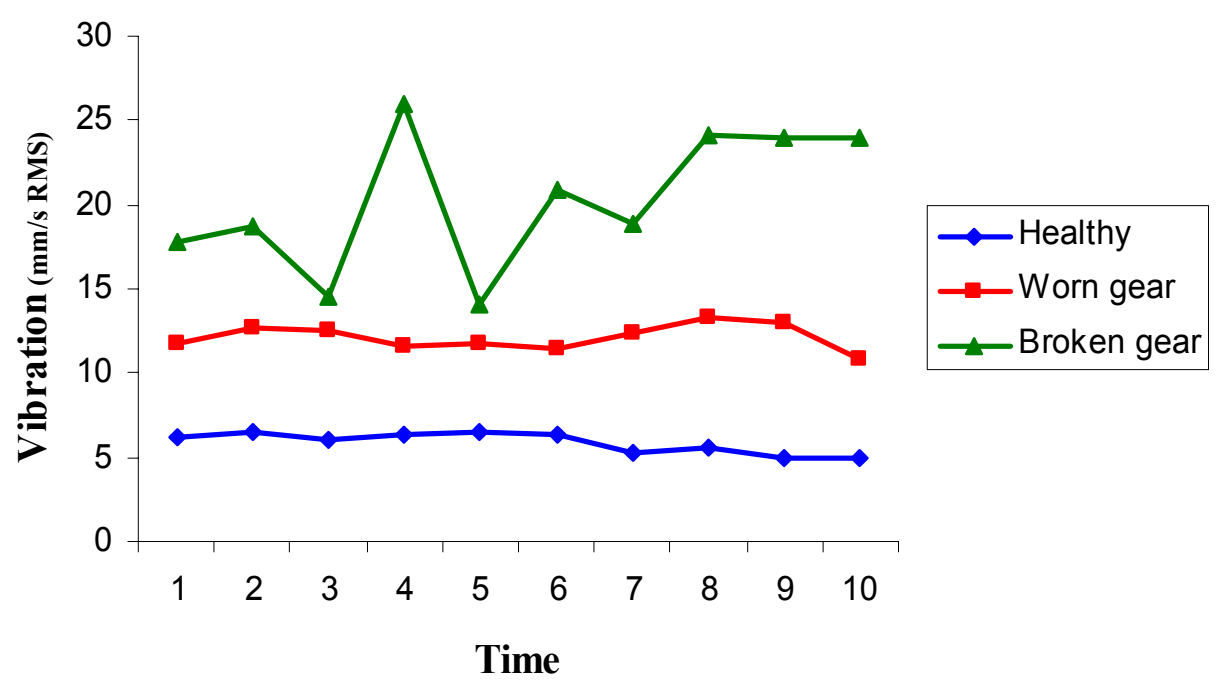

Figure 5. Comparison of Overall vibrations of gear in healthy and won and broken conditions at $1000 \mathrm{rpm}$. The graphs illustrate the effect of speed on the trend. 